\title{
Otoplasty in Childhood
}

\author{
Dr Novak Vukoje ${ }^{1}$, Dr Jon Garito ${ }^{2}$ and Milica Kovacevic ${ }^{1}$ \\ ${ }^{1}$ ENT office, Otorhinolaryngology, Petrovaradin, Serbia \\ ${ }^{2}$ The Inovator of new BAERF electrodes, USA \\ ${ }^{3}$ Chicago, USA
}

Submission: November 29, 2018; Published: December 06, 2018

*Corresponding author: Dr Novak Vukoje, ENT office, Otorhinolaryngology, Petrovaradin, Serbia

\begin{abstract}
The goal of this article is to present our results of surgical treatment of otapostasis. In the period from 2010 to 2016 the Autor operated on 26 patients with prominent ears using radio wave surgery. The average age was 10,4 years old. Surgical procedure was performed in local or general anesthesia depending on the child's age. Two hours after surgery patients left the clinic. Antibiotic and analgesic are administered for 8-10 day. The complications are rare and can be avoided by careful work. In our material complications were in the form of one side bleeding in one case that require revision. A second child was formed keloid -scaring in both ears two months after otoplasty. There were no other complications. The technique used by dr Vukoje showed that both early and late results achieved, estimated by the child, parents and surgeon, as excellent in $88,6 \%$ and in $11,4 \%$ very good. Do not restoration of the auricle in the previous position. Our results indicate that the Radio wave surgery has an advantage over classical technique especially if BAE electrodes apply. The decision of surgery should be made in agreement with the parents and present the possible complications (Figure 1).
\end{abstract}

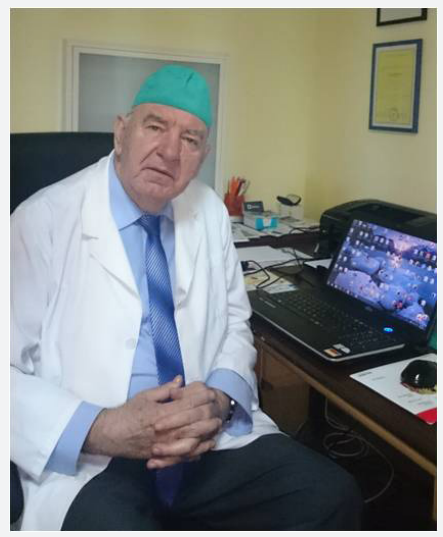

Figure 1

Keywords: Otoplasty; Otoplastica; Radiofrequency Waves; BAE Electrodes; Children's Population

\section{Introduction}

One of the most common aesthetic disturbances in childhood are protruding ears. Because of "prominent ears" about $5 \%$ of this population faces emotional problems. Psychological disorders occur after six years of life when children go to school and are bullied by their peers. The usual term they call them is "dumbo". The abduction is mainly present at birth and is usually bilateral, although it may also be unilateral. In addition to this, except for the overlapping cephalo-auricular angle, the auricles are predominantly of normal shape and architecture, although the abscess may be linked with some associated anomalies that relate to the size of the external ear, such as macrophytes, and microtia. The shape, relief, and configuration of the auricle can also occur within the pathology mentioned above. The generally accepted view is that the standing auricle needs surgical correction if the auricular-mastoid angle exceeds 35 degrees and if the distance between the helix and the head is greater than $20 \mathrm{~mm}$. The problem of solving this aesthetic disturbance is solely operational. Indications for otoplasty should always be considered together with parents and the child in order to avoid subsequent problems and misunderstandings.

The educators should be familiar with potential risks and possible complications. Otoplasty in pediatric patients has no significant impact on subsequent auricular growth. Anthropometric studies have shown that $90 \%$ of the auricular 


\section{Global Journal of Otolaryngology}

growth has already been completed in the age of 12 years. Actually, the development of the ears compared to transverse growth has been completed by the age of six, and even then, it can be recovered. Long-term monitoring of these patients has shown that otoplasty does not lead to any disorder of auricular growth and development in later life. A non-surgical correction of the prominent ears, using various devices during the first months of life, as well as wearing tape around the head that pulls and fixates the auricle toward the head, and which parents usually apply, have proved unsuccessful.

Otoplasty can be done under general or local anesthesia depending on the child's motivation and age. In children aged 610 years, general anesthesia should be used and at an older age local. There are various surgical modifications and operational approaches for "pinning" the ear shell to the head. The choice of the surgical method is not always simple because of the existence of arguments for and against each procedure. The decision is made by a surgeon with the agreement of the patient's parents. In children at this age, the auricular cartilage is soft and elastic, and the surgical procedure is less invasive. It is very important to accurately evaluate the situation and to choose smaller-sized procedures with as little trauma as possible. The roughness and thickness of the auricular cartilage plays a significant role in the selection of operational techniques. Only the cutting of the back side of the auricle in the form of a myrtle leaf is not enough to achieve lasting results of otoplastics due to the elasticity of the skin. The technique invented by Mustarde [1,2] in this population provides good cosmetic results. The operation can be carried out using a classical technique, high-frequency radio wave, an ultrasound knife, a laser, and others [3]. What technique a surgeon will use depends on what tools he has. Experience of the surgeon is important. This type of intervention is done by general surgeons, plastic surgeons, maxillofacial surgeons and otorhinolaryngologists. But primarily done by plastic surgeons. The goal of this thesis is to present our results of surgical treatment of prominent ears in 26 patients aged 6-12 years using high frequency radio waves.

\section{Material and Methods of Work}

In the period from 2010 to 2016, the author operated on 26 patients with prominent ears. Patients were predominantly males; average age was 10. 4 years old. Operations performed were an ambulatory type, of which 19 were in local anesthesia and 7 in general. The technique used were radio waves with a specially designed electrode, using the mode of cut-coagulation. Two hours after surgery, patients left the clinic.

\section{Work Technique}

The surgery begins with a retro-auricular cut of the elliptical shape on the back of the auricle, which can be extended to the mastoid skin. Then excise the skin with subcutaneous tissue, make hemostasis, make mosaic plastics on the cartilage of the concha. A few fixation seams are set through the Perichondrium cartilage, with absorbable suture thread or polydioxanone. By tightening the thread, the auricle is attached to the mastoid to the desired level [3]. It is important to note that the ear shells are not too attached to the mastoidal extension, which can give an ugly aesthetic appearance. The skin is sewn with an atraumatic suture (Figures 2-7).

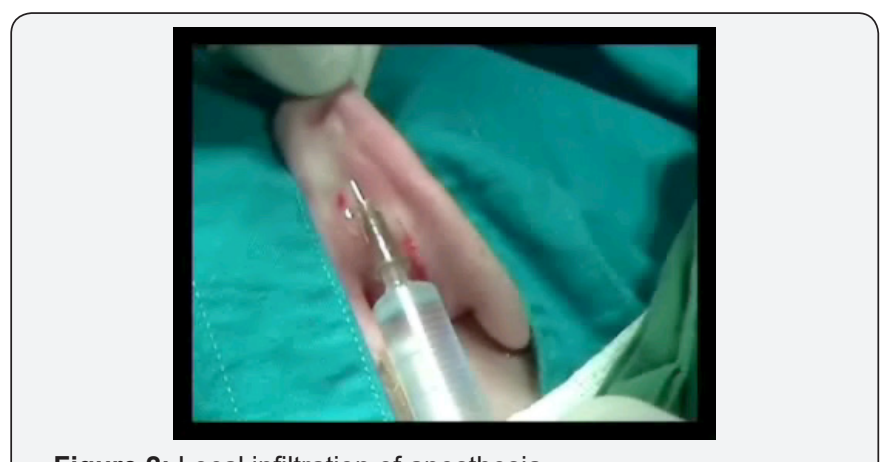

Figure 2: Local infiltration of anesthesia.

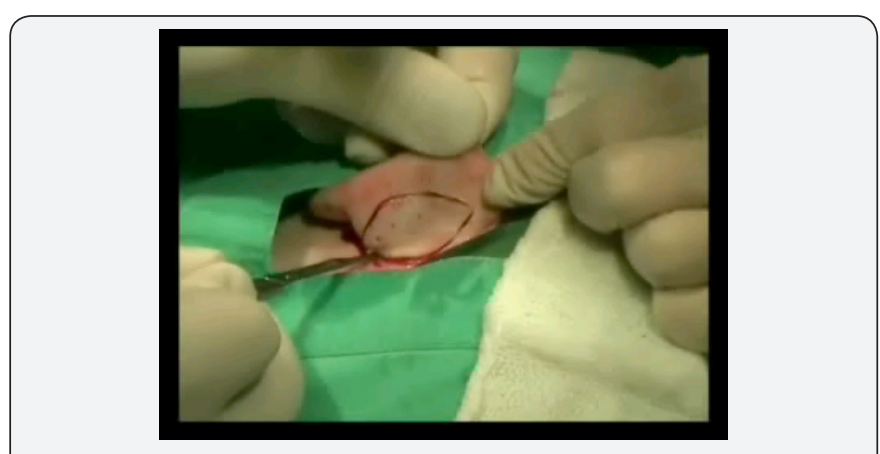

Figure 3: Excision of the skin with a classic cut.

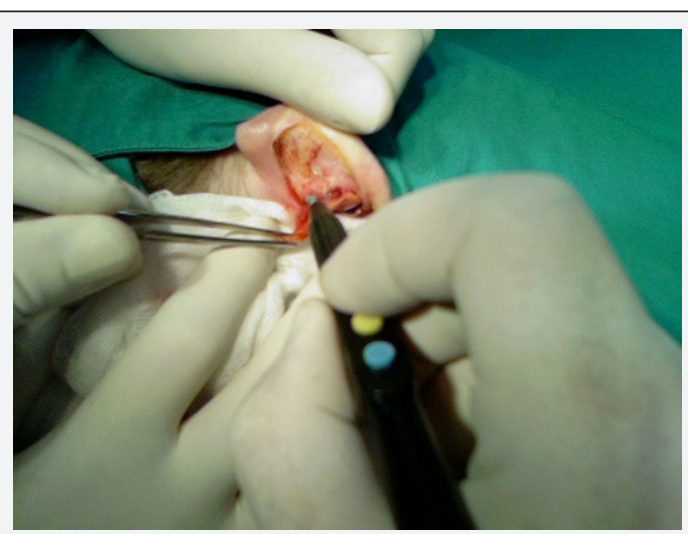

Figure 4: Work on cartilage of ear shell with radiofrequency BAE electrode (innovator dr Jon Garito US).

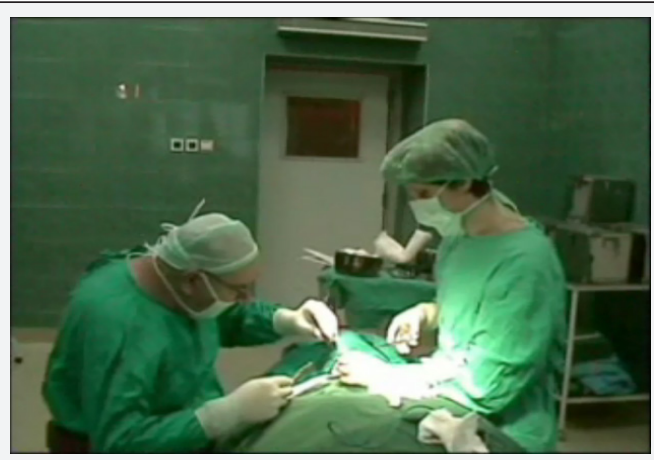

Figure 5: Completion of the operation by sewing the skin with the atraumatic suture. 


\section{Global Journal of Otolaryngology}

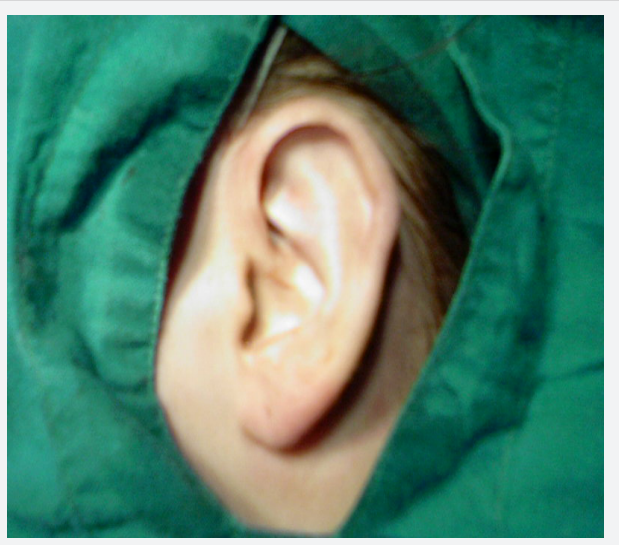

Figure 6: Appearance of the ear shell immediately after surgery where the anatomical structures and architecture of the auricle are preserved are completely preserved.

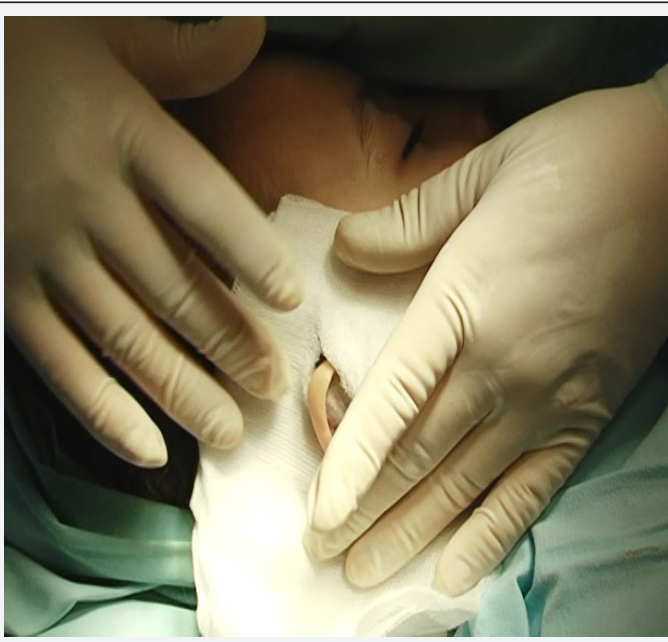

Figure 7: Bandaging post-surgery.

Bandaging is very important. First, the physiological depressions of the lateral side of the ears are filled with gauze tampons and antibacterial ointment, then a gauze (as shown in the picture) is placed retro-auricular and on the outside of the auricle. The outer side of the auricle is covered with cotton balls and over that, gauze is wrapped around the head. The next fixation is done on the second or third day. On the tenth day, the bandage is removed and at the same time the sutures are removed from the skin. It is advisable to wear tape around the ears and the head for another two to three weeks, especially during sleep.

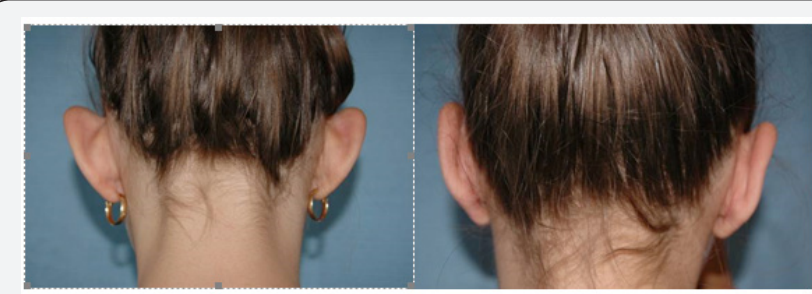

Figure 8: Appearance of external ears before and 3 weeks after otoplasty.

Antibiotics and analgesics are administered for 8-10 days (Figures 8-10).

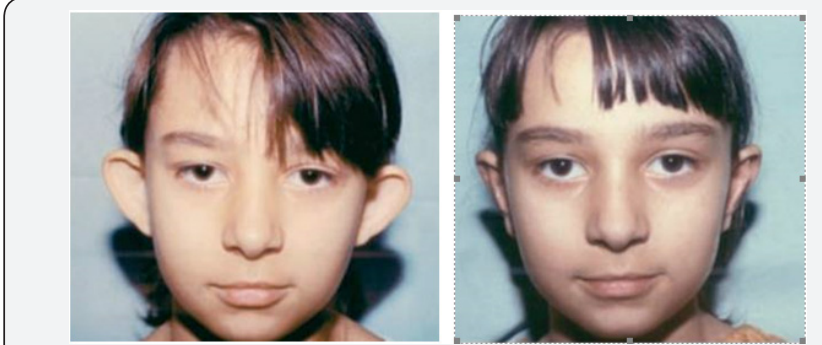

Figure 9: The appearance of the external ear before, and a month after surgery with a six-year-old child.

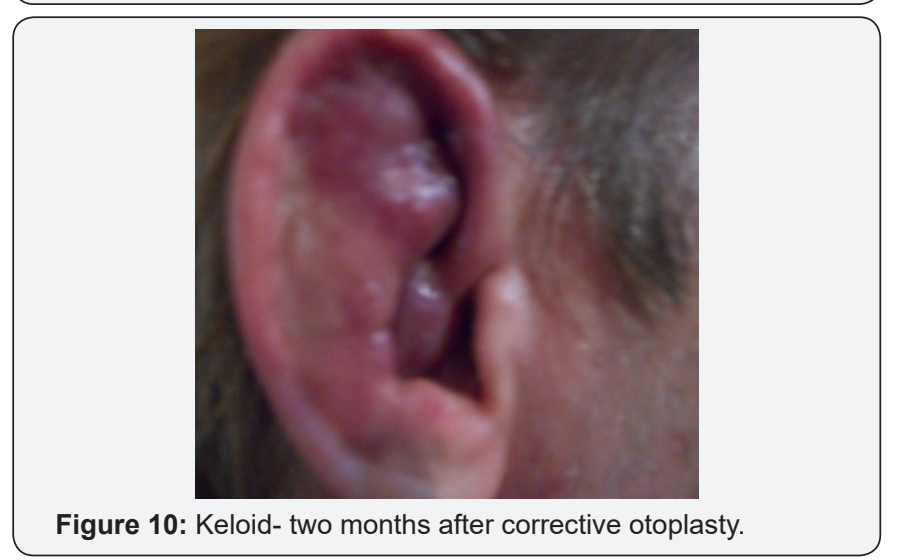

Postoperative complications following otoplasty may be early or late and lead to serious auricular deformities. Early are manifested in the form of hematoma, bleeding, skin infection, pericarditis, etc., and is delayed in the form of keloid scarring, granuloma, fistula, deformity of the ears and restoration of the auricle in the previous position, etc .

\section{Discussion}

The appropriate age for corrective otoplasty in the children's population remains controversial. Most surgeons recommend when the child is 5 years old. Otoplasty in pediatric patients does not affect subsequent auricular growth and development. Operation should in principle be done in 5-6 years of age, that is, before the start of schooling due to the psycho-social aspects of this phenomenon. At that time, the plasticity of the ear of the ear is higher [4].

A number of surgical techniques $[1,3,5,7,8]$ have been described for correction of the external ears with the aim of reducing the concha-mastoid and cefalo-auricular angle while preserving the anatomical structures and architecture of the auricle. From numerous surgical procedures and their modification of the three methods independently or in combination proved their effectiveness in correcting the ears. Mustarde [1,2] Conversu [4] and Stenstrom [8,9] had proven their superiority compared to others in terms of success. Dr Vukoje [3] is a "mosaic" of the technique, preferring the use of high frequency radio waves using Ellman Sugitron, 4.0 Mhz with a specially designed BAE electrode. The advantage of this technique compared to the classic is seen in the incision of skin without tissue pressure, minimal lesion of cartilage and perichondrium, minor bleeding, etc. which results in shorter duration of the operation and better cosmetic results with 
less complications. The "Mosaic" technique that Dr Vukoje prefers allows you to bend and reach the auricle to a mastoid-free tension with a high degree of patient and parent satisfaction. In fact, the intention of otoplasty is to preserve the normal morphology of the ears, bringing the cephalo-auricular angle to a level of 1520 degrees with a minimum rate of recurrence [9-12]. It is also important to correctly place the fixing sutures that are placed at a distance of 4-6 mm, 2-3 sutures per ear. This is significant because of the occurrence of postoperative asymmetry of the ear and later distortion of the ear shell.

\section{Conclusion}

Corrective otoplasty is a universally accepted surgical procedure in solving "protruding ears". This aesthetic operation aims to "bring" ear shells to a normal position and achieve a satisfactory cosmetic result while preserving the auricle architecture. The operation is desirable to do before the child begins school. Most authors recommend a fifth year of life. There are a number of techniques and procedures for which the surgeon will determine depending on the experience and technique at hand.

\section{References}

1. Mustardé JC (1963) The correction of prominent ears using simple mattress sutures. Br J Plast Surg 16: 170-178.

2. Mustardé JC (1967) The treatment of prominent ears by buried mattress sutures: A ten-year survey. Plast Reconstr Surg 39: 382-386.
3. Vukoje N, Jon Garito (2017) Radio-Frequency Wave Application in Esthetic Surgery of Head and Neck. Global Journal of Otolaryngology $8(4)$.

4. Converse JM, Wood Smith D (1963) Technical details in the surgical correction of the lop ear deformity. Plast Reconstr Surg 31: 118-128.

5. Mattheis S, Siegert R (2006) Techniques in otoplasty. HNO 54(8): 643656.

6. Janis JE, Rohrich RJ, Gutowski KA (2005) Otoplasty. Plast Reconstr Surg 115(4): 60e-72e.

7. Bozkir MG, Karakas P, Yavuz M, Dere F (2006) Morphometry of the external ear in our adult population. Aesthetic Plast Surg 30: 81-85.

8. Schwentner I, SchmutzhardJ, Deibl M, Sprinzl GM (2006) Healthrelated quality of life outcome of adult patients after otoplasty. J Craniofac Surg 17: 629-635.

9. Gosain AK, Recinos RF (2002) Otoplasty in children less than four years of age: surgical technique. J Craniofac Surg 13(4): 505-509.

10. Ullmann Y, Blazer S, Ramon Y, Blumenfeld I, Peled IJ, et al. (2002) Early nonsurgical correction of congenital auricular deformities. Plast Reconstr Surg 109(3): 907-915.

11. Gosain AK, Kumar A, Huang G (2004) Prominent ears in children younger than 4 years of age: what is the appropriate timing for otoplasty. Plast Reconstr Surg 114(5): 1042-1054.

12. Bauer BS, Song DH, Aitken ME (2002). Combined otoplasty technique: chondrocutaneous conchal resection as the cornerstone to correction of the prominent ear. Plast Reconstr Surg 110(4): 1033-1040

Your next submission with Juniper Publishers will reach you the below assets

- Quality Editorial service

- Swift Peer Review

- Reprints availability

- E-prints Service

- Manuscript Podcast for convenient understanding

- Global attainment for your research

- Manuscript accessibility in different formats

( Pdf, E-pub, Full Text, Audio)

- Unceasing customer service

Track the below URL for one-step submission https://juniperpublishers.com/online-submission.php 